\title{
Retraction Note to: Prevention of hip fractures by exposure to sunlight and pharmacotherapy in patients with Alzheimer's disease
}

\author{
Jun Iwamoto ${ }^{1} \cdot$ Yoshihiro Sato $^{2} \cdot$ Kiyoshi Tanaka $^{3} \cdot$ Tsuyoshi Takeda $^{1} \cdot$ Hideo Matsumoto ${ }^{1}$
}

Published online: 5 June 2018

(c) Springer International Publishing AG, part of Springer Nature 2018

\section{Retraction Note to: \\ Aging Clin Exp Res, Vol. 21, No. 4/5 277-281 \\ https://doi.org/10.1007/BF03324916}

The Editor-in-Chief has retracted this article [1] because the three studies included in the meta-analysis [2, 3, 4] (cited as references $16,17,18$ ) have been retracted due to concerns regarding the data, which has rendered the results of this meta-analysis invalid.

\section{References}

1. Iwamoto J, Sato Y, Tanaka K et al (2009) Prevention of hip fractures by exposure to sunlight and pharmacotherapy in patients with Alzheimer's disease. Aging Clin Exp Res 21:277-281. https ://doi.org/10.1007/BF03324916

The original article can be found online at https://doi.org/10.1007/ BF03324916.

Jun Iwamoto

jiwamoto@sc.itc.keio.ac.jp

1 Institute for Integrated Sports Medicine, Keio University

School of Medicine, Tokyo, Japan

2 Department of Neurology, Mitate Hospital, Fukuoka, Japan

3 Department of Food and Nutrition, Kyoto Women's

University, Kyoto, Japan
2. Sato Y, Iwamoto J, Kanoko T, Satoh K (2005) Amelioration of osteoporosis and hypovitaminosis D by sunlight exposure in hospitalized, elderly women with Alzheimer's disease: a randomized controlled trial. J Bone Miner Res 20:1327-1333. https://doi. org/10.1359/JBMR.050402

3. Sato Y, Kanoko T, Satoh K, Iwamoto J (2005) Menatetrenone and vitamin D2 with calcium supplements prevent nonvertebral fracture in elderly women with Alzheimer's disease. Bone 36:61-68. https://doi.org/10.1016/j.bone.2004.09.018

4. Sato Y, Kanoko T, Satoh K, Iwamoto J (2005) The prevention of hip fracture with risedronate and ergocalciferol plus calcium supplementation in elderly women with Alzheimer disease: a randomized controlled trial. Arch Intern Med 165:1737-1742. https ://doi.org/10.1001/archinte.165.15.1737 